\title{
Dispositional Self-Control Capacity and Trait Anxiety as Relates to Coping Styles
}

\author{
Chris Englert, Alex Bertrams, Oliver Dickhäuser \\ University of Mannheim, School of Social Sciences, Department of Psychology. \\ Email: christoph.englert@sowi.uni-mannheim.de \\ Received April 5 ${ }^{\text {th }}, 2011$; revised June 17, 2011; accepted August 14 $4^{\text {th }}, 2011$.
}

\begin{abstract}
In the present article, we analyzed the relationship between dispositional self-control capacity, trait anxiety, and coping styles. Since self-control is often crucial for adapting one's behavior to be positive, we predicted that dispositional differences in the capacity to exert self-control play a role in determining individuals coping styles. To test this assumption, we assessed participants' $(N=163)$ dispositional self-control capacity using the Self-Control Scale, and their dispositional coping styles by using the short version of the German Coping Questionnaire SVF78 (German: Stressverarbeitungsfragebogen). A path analysis supported our hypothesis; higher levels of dispositional self-control capacity were positively associated with positive coping style and negatively associated with negative coping style. Basing on attentional control theory, we further assumed that this relationship was mediated by trait anxiety. In a second study based on a sample of $N=98$ participants, we additionally applied the trait version of the State-Trait Anxiety Inventory. The results of a path analysis revealed that trait anxiety mediated the relationship between dispositional self-control capacity and coping styles. The results suggest that it may be useful to take a closer look at the role of self-control in the anxiety-coping relationship.
\end{abstract}

Keywords: Anxiety, Coping, Emotion, Ego Depletion, Self-control, Self-regulation

\section{Introduction}

Chronic stress can cause serious health problems such as depression or coronary heart disease (e.g., Miller \& Blackwell, 2006), which is why an appropriate handling of stress is inevitable. Each individual has his or her own way of dealing with stressful encounters. The strategies, which are chosen by an individual in order to deal with stress, are referred to as coping, meaning individual responses to stressful events (Folkman \& Lazarus, 1980). Coping can either be seen as a personality trait (coping styles) or as a situational state (Endler \& Kocovski, 2001). Viewing coping as a personality trait describes an individuals' habitual preference to use particular coping strategies in stressful situations, while situational coping is the actual behavior in a stressful situation, which results from the interaction between coping styles with situational and personal characteristics (Endler \& Parker, 1994). Although many researchers view personality traits as immutable aspects of personality (e.g. Costa \& McCrae, 1997) there is also another point of view: Personality aspects can change over the course of a life time because of complex interactions between an individual and his or her environment (Baltes, 1987; Baltes, Staudinger, \& Lindenberger, 1999).

According to Lazarus and Folkman (1984), individuals are eager to reduce feelings of stress, and they initiate certain coping strategies in order to do so. However, not every coping strategy will lead to a reduction of the perceived stress. Some coping strategies are rather maladaptive in specific situations; that is, they potentially increase instead of decrease perceived stress. Therefore, these strategies are termed negative coping strategies, whereas strategies that actually decrease stress are termed positive coping strategies (e.g., Carver, Scheier, \& Weintraub, 1989). One approach that explicitly differentiates between positive and negative coping strategies is postulated by Janke and Erdmann (2002). The authors assign positive and negative coping strategies to two broad factors, labelled positive and negative coping styles, where here, coping styles are taken to mean a habitual tendency to use specific coping strategies in stressful situations. Strategies that are subsumed under the factor positive coping style include denial of guilt, distraction, minimization, positive self-instruction, reaction control, situation control, and substitute gratification. Strategies assigned to the factor negative coping style include escape, resignation, self-blame, and worrying.

A critical variable that seems to have an important impact on coping with stress is self-control (Baumeister, Faber, \& Wallace, 1999). Self-control describes the process of controlling and altering predominant responses in order to bring them in line with social or individual norms. Therefore, self-control is highly adaptive and helps individuals to achieve certain goals (Baumeister, Vohs, \& Tice, 2007). However, there are dispositional differences in the capacity to exert self-control which are associated with a broad variety of adaptive behaviors and the ability to successfully regulate emotions (Tangney, Baumeister, $\&$ Boone, 2004). For example, higher levels of dispositional self-control capacity are related to less alcohol abuse under stress, less binge-eating, better interpersonal skills, as well as lower levels of trait anxiety (Finkel \& Campbell, 2001; Tangney et al., 2004).

In a study conducted by Mischel and colleagues (Mischel, Shoda, \& Peake, 1988), preschool participants' ability to delay gratification, a form of self-control, was a strong predictor of their coping ability in a ten year follow up study. However, in this study, individuals' coping ability was only assessed via one item rating the individuals' general coping ability in comparison to other individuals of their age, which does not seem to be an appropriate measure of the variety of coping styles that have been identified by research. Gailliot and colleagues (Gailliot, Schmeichel, \& Baumeister, 2006; Gailliot, Schmeichel, \& Maner, 2007) have shown that individuals require self-control to cope with thoughts about death. In their studies, the authors 
primed participants with death and found out that participants with higher levels of dispositional self-control capacity reported less thoughts about death, implying they were more adapt at coping with stress compared to participants with lower levels of dispositional self-control. However, this particular study did not yield any results about the use of specific coping styles when confronted with death. As far as we know, no study has explicitly investigated the relationship between dispositional selfcontrol capacity and coping styles. So, one aim of the present study is to test whether there is a relationship between dispositional self-control capacity and individuals' dispositional coping styles. We postulate in Study 1 that higher levels of dispositional self-control are positively associated with a positive coping style and negatively associated with a negative coping style.

However, we suspect the anticipated relationship between dispositional self-control capacity and coping styles to be mediated by trait anxiety. Over the course of the last century, plenty of studies have investigated the phenomena of anxiety and its effects on all different kinds of facets of human thinking and human behavior, for instance, on performance, on mental and physical health and well-being, and on social interactions (e.g., Endler \& Kocovski, 2001; Gaudry, Vagg, \& Spielberger, 1975; Hembree, 1988). Like coping, anxiety can be defined as either a situational state or as a personality trait, the latter meaning a habitual tendency to feel anxious in specific situations (Endler \& Kocovski, 2001; Gaudry et al., 1975; Spielberger, Gorsuch, \& Lushene, 1970). Individuals with higher levels of dispositional self-control capacity are more adept at regulating their emotions (Gailliot et al., 2006; Gailliot et al., 2007) and report lower levels of trait anxiety (Tangney et al., 2004). Bertrams, Englert and Dickhäuser (2010) experimentally manipulated participants' momentary capacity to exert self-control and found that trait test anxiety and state anxiety following a test announcement were substantially positively related among participants whose capacity to exert self-control was reduced; however, participants with higher levels of trait test anxiety did not develop higher levels of state anxiety after the test announcement compared to participants lower in trait test anxiety when their capacity to exert self-control was intact. Therefore, we assume that self-control is needed to regulate anxiety.

Furthermore, highly anxious individuals tend to use rather maladaptive coping strategies (Bolger, 1990; Endler \& Parker, 1990; Spielberger \& Vagg, 1995; Zeidner, 1998). We are trying to explain this pattern by introducing the attentional control theory developed by Eysenck and colleagues (Eysenck, Derakshan, Santos, \& Calvo, 2007). Eysenck et al. have stated that anxiety impairs the functioning of the central executive (Baddeley, 1986) by reducing its limited capacity, leading to impairments in attentional control. This causes an imbalance between the two attentional systems controlled by the central executive: The top-down goal driven system, which helps individuals to achieve certain goals through planned behavior, and the bottom-up stimulus driven system, which is influenced by salient stimuli and thus prevents systematic information processing (Corbetta \& Shulman, 2002; Yantis, 1998). Under anxiety, the bottom-up stimulus driven attentional system dominates because it requires less cognitive capacity. The dominance of the bottom-up system mainly affects two basic control functions of the central executive (Miyake et al., 2000): Inhibition and shifting. Inhibition means the ability to resist distraction from task-irrelevant stimuli. Shifting describes the ability to flexibly shift the attention back and forth between different stimuli, depending on specific situational or personal demands. Thus far, attentional control theory was only applied to enligh- ten the negative influence of anxiety on cognitive performance (e.g., Derakshan, Ansari, Hansard, Shoker, \& Eysenck, 2009; Eysenck et al., 2007).

We want to expand the adaptability of attentional control theory by explaining the negative influence of anxiety on coping since shifting and inhibition seem to be important preconditions for most positive coping strategies, but not so much for negative coping strategies. We will explain this statement by referring to the coping strategies assessed in the German Coping Questionnaire (Janke \& Erdmann, 2002). For the use of strategies subsumed under the factor positive coping style (i.e., denial of guilt, distraction, minimization, positive self-instruction, reaction control, situation control, and substitute gratification) individuals are dependent on the inhibition and shifting function. In the following, we refer to evidence supporting this assumption.

Bar-Haim and colleagues (Bar-Haim, Lamy, Pergamin, Bakermans-Kranenburg, \& van IJzendoorn, 2007) reported that anxiety is related to an attentional bias towards threat-related stimuli. This finding, on the one hand, can be explained by an impaired inhibition function, meaning that anxious individuals cannot inhibit their impulse to mainly focus on the threatening stimulus. Therefore, anxious individuals are supposed to have problems applying the positive coping strategies reaction control (i.e., remain calm) and situation control (i.e., analyze the situation objectively) when facing a stressful situation. On the other hand, the attentional bias can also be explained by an impaired shifting function, so that anxious individuals are not capable of shifting their attention away from the threatening stimuli to more pleasant stimuli. Therefore, anxious individuals are supposed to have problems using the positive coping strategies distraction (i.e., turn the attention away from the threat), minimization (i.e., view their own problems as less threatening than others' problems), and substitute gratification (i.e., turn the attention away from the threat and do something more pleasant instead) when confronted with adversity. Additionally, the remaining two positive coping strategies (i.e., denial of guilt and positive self-instruction) are supposed to be dependent on the shifting and inhibition function as well: In order to be able to deny feelings of guilt, one has to inhibit negative thoughts resulting from a guilty conscious. Likewise, in order to be able to instruct oneself positively during a stressful encounter, one has to shift attention away from the threat and has to start thinking about something positive instead.

Apart from Bar-Haim and colleagues (2007), Eysenck, MacLeod, and Mathews (1987) deliver some support for our assumptions as well. In their studies, highly trait anxious individuals show an interpretive bias since they are more likely to interpret homophones (e.g., pain vs. pane; die vs. dye) in a threatening way. This finding can also be explained by an impaired ability to inhibit the tendency to focus solely on threatening aspects of stimuli, as well as by an impaired ability to shift the attention away from threatening to more positive aspects of stimuli.

However, inhibition and shifting should not be essential for the coping strategies subsumed under the factor negative coping style (i.e., escape, resignation, self-blame, and worrying). For instance, in order to escape or to resign, one does not merely inhibit impulses, but instead one either avoids the situation entirely or obeys the threatening situation and gives up. Also, shifting is not essential for the usage of negative coping strategies because worrying or self-blaming describe a tendency to keep thinking about the threat rather than shifting the attention away from it. Apart from the German Coping Questionnaire 
(Janke \& Erdmann, 2002), the coping strategies assessed in other well established coping inventories, such as in the Ways of Coping Questionnaire (WOCQ; Folkman \& Lazarus, 1988) or the COPE Inventory (Carver et al., 1989), can be rated in terms of their dependence on the inhibition and shifting function as well; however, this will not be of central relevance for the present paper.

All in all, the hypothesis of Study 2 can be summed up as follows: The relationship between dispositional self-control capacity and coping styles is mediated by trait anxiety, since individuals with lower dispositional self-control capacity are more likely to experience higher levels of anxiety because they have less capacity to regulate their anxiety. Anxiety reduces the capacity of the central executive, which impairs the inhibition and shifting function. Every individual is somehow trying to deal with the aversive feelings of stress (Zeidner, 1998), yet the impairments of the inhibition and shifting function can have an influence on individuals' coping styles: Anxious individuals should report a positive coping style less frequently than non-anxious individuals, since for this style, the inhibition and shifting functions are inevitable. Instead, anxious individuals should report a negative coping style more often than nonanxious ones because they do not have any other choice: The fact that their inhibition and shifting functions are impaired does not allow them to apply a positive coping style. Still, anxious individuals also react to stress in a specific way, and by that they should report a negative coping style more often than non-anxious individuals because for the application of this style, the inhibition and shifting functions are not required.

\section{Study 1}

The aim of the present study was to test whether dispositional self-control capacity is related to habitual coping styles. We postulated that higher levels of dispositional self-control are positively associated with a positive coping style and negatively associated with a negative coping style.

\section{Methods}

\section{Participants}

Participants included 163 students ( 100 female; $M_{\text {age }}=15.37$, $\left.S D_{\text {age }}=0.71\right)$ from a comprehensive secondary school (German Gymnasium) from a middle-sized town in Germany. Informed consent was obtained by parents and students before the study was commenced.

\section{Materials and Procedures}

All data was collected during regular class sessions. First, participants were asked to report their demographic data which included information about their age, sex, and their mother tongue.

Next, participants worked on the German adaption of the short form of the Self-Control Scale, which measures dispositional self-control capacity (SCS; Tangney et al., 2004; German Bertrams \& Dickhäuser, 2009). The participants needed to answer 13 items on a 5-point scale ranging from 1 (not at all) to 5 (very much). Four items referred to high self-control (e.g., "I am good at resisting temptation") while the other nine items referred to low self-control (e.g., "I have a hard time breaking bad habits"). These nine items had to be reversely coded, so that higher values indicated a higher dispositional self-control capacity. In the present sample, the scale showed a sufficient internal consistency (Cronbach's $\alpha=.81$ ).
In a next step, we assessed participants' dispositional coping styles using the aforementioned short version of the German Coping Questionnaire SVF78 (Janke \& Erdmann, 2002). Participants were asked to rate 78 items that all start with the introductory statement "When I am disturbed, irritated, or upset by something or someone..." followed by the actual item on a 5-point scale from 1 (never) to 5 (always). For instance, an item for the positive coping strategy reaction control would be "...I am trying to control my behavior" and an item for the negative coping strategy resignation would be "... I feel helpless". In the present sample, the reliability for positive coping style (Cronbach's $\alpha=.87$ ) as well as for negative coping style (Cronbach's $\alpha=.89$ ) was sufficient. The proposed factor structure of the SVF78 has been replicated in a study by Ising and colleagues (Ising, Weyers, Janke, \& Erdmann, 2001), indicating that in the present study, the assignment of the specific coping strategies to either positive or negative coping styles was identical to the assignment reported by Janke and Erdmann (2002).

\section{Results}

The mean of the SCS was $2.83(S D=0.63)$, the mean for positive coping style was $3.07(S D=0.41)$, and for negative coping style, the mean was $2.77(S D=0.73)$.

We tested our hypothesis that higher levels of dispositional self-control are positively associated with a positive coping style and negatively associated with a negative coping style by using path analysis including dispositional self-control capacity as a predictor for positive coping style and for negative coping style. We applied AMOS 18.0 to calculate the model. The relationships between the variables in this model were as expected: Higher levels of dispositional self-control capacity were positively associated with positive coping style $(\beta=.11, p$ $=.05)$ and negatively associated with negative coping style $(\beta=$ $-.32, p<.001)$. There was a negative relationship between positive and negative coping style $(\beta=-.18, p=.03)$. Figure 1 presents the path analysis diagram. The results support our hypothesis: Dispositional self-control was related to habitual coping styles. These results deliver im- portant additional information to previous studies investigating the relationship between dispositional self-control and coping (Mischel et al., 1988; Gailliot et al., 2006; Gailliot et al., 2007), by distinguishing between different coping stiles.

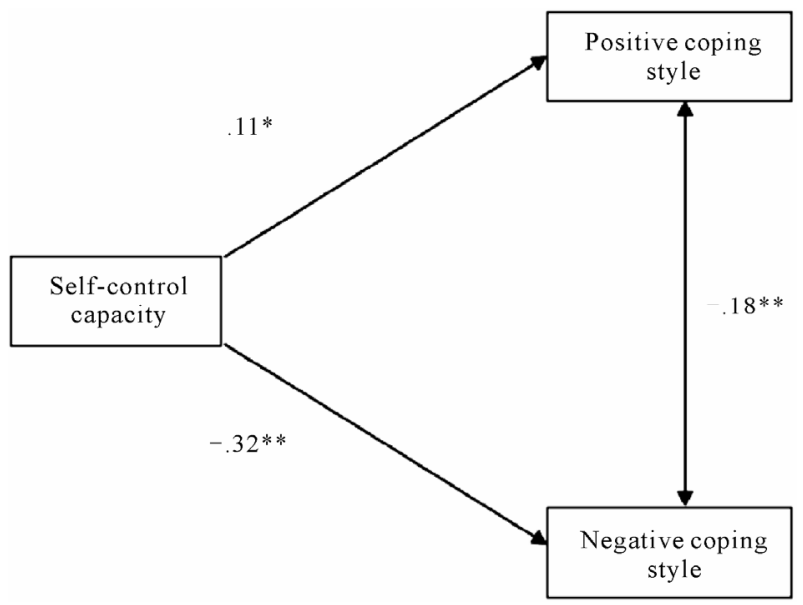

Figure 1.

Path analysis diagram for the relation between dispositional self-control capacity and coping styles. Displayed are the standardized path coefficients. ${ }^{*} p<.05 . * * p<.01$ 


\section{Study 2}

In Study 2 we focused on explaining the relationship between dispositional self-control capacity and the coping styles we found in Study 1. We assumed that trait anxiety mediated this relationship. We explain this expected pattern in two steps: First, individuals with higher levels of dispositional self-control capacity should be more adept at regulating their emotions, and thus report lower levels of anxiety than individuals with lower values of dispositional self-control capacity. Second, as proposed by the attentional control theory (Eysenck et al., 2007) we assumed that higher levels of trait anxiety would be associated with impairments in the shifting and inhibition functions controlled by the central executive. To exercise the coping strategies that Janke and Erdmann (2002) subsumed under positive coping style, one needs to inhibit predominant responses to stressors; for example, applying the minimization coping strategy can only be achieved if the individual is capable of inhibiting his or her dominant tendency to panic when confronted with a stressful situation. Or when applying the situation control strategy, one also needs to flexibly shift attention away from the stressors and focus on the problem itself. Therefore, trait anxiety is supposed to be negatively related to a positive coping style. On the other hand, in order to use strategies subsumed under negative coping style, one needs neither to inhibit predominant response (e.g., escape), nor to shift the attention away from the threatening stimuli (e.g., resignation). For this reason, we predicted that trait anxiety is positively related to a negative coping style.

\section{Methods}

\section{Participants}

The analyses of Study 2 are based on a sample of 98 participants ( 72 female; $M_{\text {age }}=26.53 ; S D_{\text {age }}=8.23$ ). The participants were recruited by sending an online link to students registered on anonymous mailing lists we received from two German universities. They worked on an online survey for approximately 20 minutes. As a reward for their participation, the participants had the chance to win one of five 20 Euro gift vouchers (at that time approximately US\$25). Informed consent was obtained before the study was commenced.

\section{Materials and Procedures}

All data was collected using a specific online survey tool. First, participants were asked to report their demographic data which included information about their age, sex, profession, and their mother tongue.

This study again contained the SCS to assess participants' dispositional level of self-control capacity (Tangney et al., 2004; German: Bertrams \& Dickhäuser, 2009). The internal consistency for the SCS was sufficient (Cronbach's $\alpha=.85$ ).

Next, coping styles were measured with the SVF78 (Janke \& Erdmann, 2002). Internal consistencies for the positive coping style (Cronbach's $\alpha=.84$ ) and for the negative coping style (Cronbach's $\alpha=.89$ ) were satisfactory.

Other than these two measures, we also administered the German trait version of the State-Trait Anxiety Inventory (STAI; Spielberger et al., 1970; German: Laux, Glanzmann, Schaffner, \& Spielberger, 1981) to measure participants' degree of trait anxiety. The STAI-trait consists of 20 items, with 13 items assessing the presence of anxiety, such as "I get in a state of tension or turmoil as I think over my recent concerns and interests", and with seven items assessing the absence of anxiety such as "I feel rested". The items were answered on a 4-point scale ranging from 1 (almost never) to 4 (almost always). The seven items measuring the absence of anxiety had to be reversely coded, meaning that higher values represented higher levels of trait anxiety. The internal consistency of the STAI in the present sample was good (Cronbach's $\alpha=.89$ ).

\section{Results}

In this study, the mean for the SCS was $3.16(S D=0.69)$, the mean for positive coping style was $3.15(S D=0.47)$ and for negative coping style, the mean was $2.86(S D=0.71)$. Mean score for the STAI-trait was $2.06(S D=0.44)$.

We used path analysis in order to test whether the relationship between dispositional self-control capacity and coping styles was mediated by trait anxiety. In a first model, we included dispositional self-control capacity as a predictor for positive coping style and for negative coping style. The relationships between the variables included in this model were as expected: Higher levels of dispositional self-control capacity were positively related to positive coping style $(\beta=.13, p$ $=.06)$, and negatively related to negative coping style $(\beta=-.49$, $p<.001)$.

In a second path analysis, we included dispositional selfcontrol capacity, trait anxiety, and positive and negative coping style to test the postulated mediation hypothesis. Figure 2 presents the path analysis diagram. In evaluating the postulated model we used multiple indexes of fit since each of these indexes evaluates the model slightly differently, and a good fit from these various indexes increases the confidence in the model (Hu \& Bentler, 1995). Apart from the chi-square test statistic, we have reported the Comparative Fit-Index (CFI), the Root Mean Square-Error of Approximation (RMSEA), and the Standardized-Root-Mean-Residual (SRMR). According to $\mathrm{Hu}$ and Bentler (1999) a good model fit is indicated if the reported fit indexes meet the following cut-off-criteria: CFI $\geq .95$, RMSEA $\leq 0.08$, and SRMR $\leq .11$. The fit for the model was as follows: $\chi^{2}(2,98)=2.99, p=.22, \mathrm{CFI}=.99$, RMSEA $=.07$, and SRMR $=.03$. The reported indexes suggest a good fit of the proposed model. Also, the relationships between the included variables were as expected, indicated by the standardized path coefficients: Higher levels of dispositional self-control capacity were negatively related to trait anxiety $(\beta=-.50, p<.001)$, and trait anxiety was negatively related to positive coping style $(\beta=$ $-.37, p<.001)$ and positively related to negative coping styles $(\beta=.75, p<.001)$. There was a negative relationship between positive and negative coping style $(\beta=-.20, p=.04){ }^{1}$

The results of our analysis support our hypothesis that the relationship between dispositional self-control and coping styles is mediated by trait anxiety.

\section{General Discussion}

In this paper, we analyzed the relationship between dispositional self-control capacity, trait anxiety, and individuals' coping styles. In a first study, we postulated that higher levels of dispositional self-control capacity are associated with positive

\footnotetext{
${ }^{1}$ If we additionally included direct paths from dispositional self-control capacity to positive coping style and negative coping style, the overall model did not fit. However, as this model has no $d f$, we refrain from reporting the fit indexes. More importantly, the standardized path coefficients revealed that there was no significant relationship between dispositional self-control capacity and positive coping style $(\beta=.01, p=.95)$ and negative coping style $(\beta=-.14, p=.09)$ in this path analysis, delivering additional support for our postulated mediation hypothesis.
} 


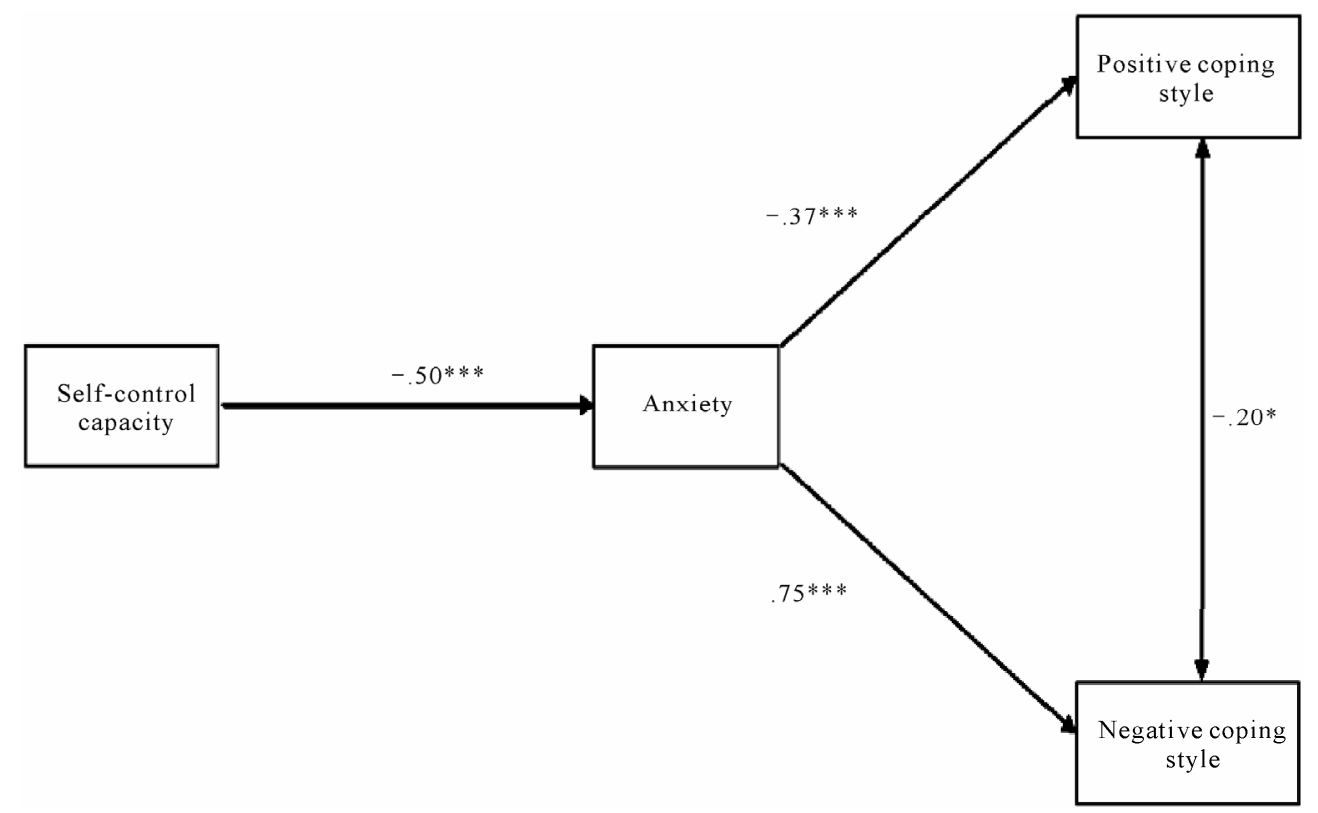

Figure 2.

Path analysis diagram for testing the mediating role of trait anxiety in explaning the relation between dispositional self-control capacity and coping styles. Displayed are the standardized path coefficients. ${ }^{*} p<.05 .{ }^{* *} p<.001$.

coping style and negatively related to negative coping style. The reason for the assumption is based on findings in the field of self-control research, which indicate that people with higher levels of dispositional self-control capacity are more adept in handling themselves under stress (e.g., Gailliot et al., 2006; Gailliot et al., 2007; Tangney et al., 2004). Our results support our hypothesis.

We included trait anxiety as an additional variable in Study 2 to explain the findings of Study 1. First, like in Study 1, we assumed that dispositional self-control capacity is positively related to positive coping style and negatively related to negative coping style. Again, our results supported this hypothesis. We further assumed that trait anxiety is negatively related to positive coping style and positively related to negative coping style. The findings of Study 2 also delivered evidence for this second hypothesis. To test whether the relationship between dispositional self-control capacity and coping styles is mediated by trait anxiety, we utilized path analysis. Results were as expected, since trait anxiety mediated the relationship between dispositional self-control capacity and coping styles. We explain these results with findings in the field of self-control research, indicating that self-control is required to down-regulate anxiety (Bertrams et al., 2010). We further applied the attentional control theory (Eysenck et al., 2007) as an explanation of our results. Higher levels of anxiety impair two primary functions of the central executive: Inhibition and shifting. For the positive coping strategies assessed in our studies, these two functions are essential because, for example, one needs to inhibit predominant responses to stress in order to minimize averse feelings, and one needs to shift attention away from threatening stimuli to control the stressful situation. On the other hand, to use negative coping strategies, one is neither dependent on the inhibition nor on the shifting function. For instance, individuals having a dispositional tendency to resign or worry in stressful situations do not have to have the ability to shift their attention away from threatening stimuli. There is also no need to inhibit negative thoughts in order to be able to apply escape or self-blame strategies. Thus, the higher the anxiety, the more difficult it is supposed to be to apply positive coping strategies, whereas the usage of negative coping strategies should not be impaired.

Although in the present studies self-control capacity was included as a dispositional trait, it would be worthy to also look at self-control as a situational state in future studies. Research has shown that self-control is based on a limited resource (Baumeister, Bratslavsky, Muraven, \& Tice, 1998) and after a primary exertion of self-control, the resource is temporarily depleted (a state referred to as ego-depletion), leading to subsequently impaired self-control. Baumeister et al. (1999) postulated that one major consequence of stress is that the self-control resource becomes depleted following a coping act (Baumeister et al., 1999; Muraven, Tice, \& Baumeister, 1998). However, no study, as far as we know, has yet investigated the other route in the self-control-coping relationship. Namely, that the self-control resource affects coping. A depleted self-control resource should impair individuals' momentary ability to control anxiety (Bertrams et al., 2010). As a consequence, anxiety should negatively affect the inhibition and shifting function of the central executive (Eysenck et al., 2007) and finally lead to maladaptive situational coping. To test this assumption, an experimental design could be applied in which participants' self-control resource would be depleted in one condition but not in a second condition. Such an approach would enable one to not only report correlational relationships between self-control, anxiety, and coping styles but to also discover the causal role of self-control.

This leads to a limitation of our study. The study design does not allow inferring causal relationships between the involved variables. Although the theoretical approach underlying the present studies suggests causal directions in the relationships between the variables, the question of causality has not been empirically addressed. Testing the causal influence of anxiety on situational coping may not be as easy as testing the influence of self-control capacity. In the case of self-control capacity, a 
manipulation of the self-control resource is quite common (e.g., Muraven et al., 1998). In contrast, an experimental manipulation of anxiety, meaning actively inducing anxiety, may be problematic from an ethical point of view.

A second limitation regards the exclusive use of self-report measures, as all results of our studies are based on self-reports. Especially in the SVF78 (Janke \& Erdmann, 2002), individuals rated their likely behaviour in a hypothetical setting; namely, how they would react if they were disturbed, irritated, or upset by something or someone. Therefore, future studies should not only assess individuals' coping behavior via self-report measures, but also by watching their actual coping behavior in a specific situation.

The results presented in this article deliver a possible practical implication: Higher levels of dispositional self-control capacity were associated with lower levels of anxiety and with positive coping style, so it may be useful to focus on self-control capacity in order to enable individuals to regulate their anxiety and to enhance individuals' coping skills. Baumeister and colleagues (1998) compared the self-control resource to a muscle that can grow following regular workout. Several training programs have been conducted to improve self-regulatory strength (for an overview see Baumeister, Gailliot, DeWall, \& Oaten, 2006). For example, in a study conducted by Gailliot and colleagues, participants were instructed to use their nonpreferred hand for everyday activities like brushing teeth or avoiding using swear words over a 2-week period, which improved their ability to exercise self-control (Gailliot, Plant, Butz, $\&$ Baumeister, 2004). Following the results of our studies, a regular exertion of self-control could increase individuals' self-control capacity and thus reduce their anxiety, which, in turn, could improve their coping skills.

All in all, the present article gives a first indication that self-control capacity is a valuable variable that should be considered in anxiety and coping research.

\section{Acknowledgments}

The studies reported in this article have been supported by a grant of the University of Mannheim to Alex Bertrams (AZ: 7530.0) and a grant from the German Research Foundation to Oliver Dickhäuser (DI 929/2-3). We thank Anastasia Byler for copyediting.

\section{References}

Baddeley, A. D. (1986). Working memory. Oxford, England: Clarendon Press.

Baltes, P. B. (1987). Theoretical propositions of lifespan developmental psychology: on the dynamics between growth and decline. Developmental Psychology, 23, 611-626.

Baltes, P. B., Staudinger, U. M., \& Lindenberger, U. (1999). Lifespan psychology: Theory and application to intellectual functioning. Annual Review of Psychology, 50, 471-507.

Bar-Haim, Y., Lamy, D., Pergamin, L., Bakermans-Kranenburg, M. J., \& van IJzendoorn, M. H. (2007). Threat-related attentional bias in anxious and non-anxious individuals: A meta-analytic study. Psychological Bulletin, 133, 1-24. doi:10.1037/0033-2909.133.1.1

Baumeister, R. F., Bratslavsky, E., Muraven, M., \& Tice, D. M. (1998). Ego depletion: is the active self a limited resource? Journal of Personality and Social Psychology, 74, 1252-1265.

doi:10.1037/0022-3514.74.5.1252

Baumeister, R. F., Faber, J. E., \& Wallace, H. M. (1999). Coping and ego depletion: Recovery after the coping process. In C. R. Snyder (Ed.), Coping: The psychology of what works (pp. 50-69). Oxford,
England: University Press.

Baumeister, R. F., Gailliot, M., DeWall, C. N., \& Oaten, M. (2006). Self-regulation and personality: How interventions increase regulatory success, and how depletion moderates the effects of traits on behavior. Journal of Personality, 74, 1773-1802. doi:10.1111/j.1467-6494.2006.00428.x

Baumeister, R. F., Vohs, K. D., \& Tice, D. M. (2007). The strength model of self-control. Current Directions in Psychological Science, 16, 351-355. doi:10.1111/j.1467-8721.2007.00534.x

Bertrams, A., \& Dickhäuser, O. (2009). Messung dispositioneller Selbstkontroll-Kapazität. Eine deutsche Adaptation der Kurzform der Self-Control Scale (SCS-K-D) [Measuring dispositional self-control capacity: A German adaptation of the Brief Self-Control Scale (SCS-K-D)]. Diagnostica, 55, 2-10. doi:10.1026/0012-1924.55.1.2

Bertrams, A., Englert, C., \& Dickhäuser, O. (2010). Self-control strength in the relation between trait test anxiety and state anxiety. Journal of Research in Personality, 44, 738-741. doi:10.1016/j.jrp.2010.09.005

Bolger, N. (1990). Coping as a personality process: A prospective study. Journal of Personality and Social Psychology, 59, 525-537. doi:10.1037/0022-3514.59.3.525

Carver, C. S., Scheier, M. F., \& Weintraub, J. K. (1989). Assessing coping strategies: A theoretically based approach. Journal of Personality and Social Psychology, 56, 267-283. doi:10.1037/0022-3514.56.2.267

Corbetta, M., \& Shulman, G. L. (2002). Control of goal-directed and stimulus-driven attention in the brain. Nature Reviews Neuroscience, 3, 201-215. doi: $10.1038 / \mathrm{nrn} 755$

Costa, P. T. Jr., \& McCrae, R. R. (1997). Longitudinal stability of adult personality. In R. Hogan, J. Johnson and S. Briggs (Eds.), Handbook of personality psychology (pp. 269-290). San Diego, CA: Academic Press.

Derakshan, N., Ansari, T. L., Hansard, M., Shoker, L., \& Eysenck, M. W. (2009). Anxiety, inhibition, efficiency, and effectiveness. An investigation using the antisaccade task. Experimental Psychology, 56, 48-55. doi:10.1027/1618-3169.56.1.48

Endler, N. S., \& Kocovski, N. L. (2001). State and trait anxiety revisited. Anxiety Disorders, 15, 231-245. doi:10.1016/S0887-6185(01)00060-3

Endler, N. S., \& Parker, J. D. A. (1990). Multidimensional assessment of coping: A critical evaluation. Journal of Personality and Social Psychology, 58, 844-854. doi:10.1037/0022-3514.58.5.844

Endler, N. S., \& Parker, J. D. A. (1994). Assessment of multidimensional coping: Task, emotion, and avoidance strategies. Psychological Assessment, 6, 50-60. doi:10.1037/1040-3590.6.1.50

Eysenck, M. W., Derakshan, N., Santos, R., \& Calvo, M. G. (2007). Anxiety and cognitive performance: Attentional control theory. Emotion, 7, 336-353. doi:10.1037/1528-3542.7.2.336

Eysenck, M. W., McLeod, C., \& Mathews, A. (1987). Cognitive functioning and anxiety. Psychological Research, 49, 189-195. doi:10.1007/BF00308686

Finkel, E. J., \& Campbell, W. K. (2001). Self-control and accommodation in close relationships: An interdependence analysis. Journal of Personality and Social Psychology, 81, 263-277. doi:10.1037/0022-3514.81.2.263

Folkman, S., \& Lazarus, R. S. (1980). An analysis of coping in a middle-aged community sample. Journal of Health and Social Behavior, 21, 219-239. doi:10.2307/2136617

Folkman, S., \& Lazarus, R. S. (1988). Manual for the ways of coping questionnaire. Palo Alto, CA: Consulting Psychologists Press.

Gailliot, M. T., Plant, E. A., Butz, D. A., \& Baumeister, R. F. (2004). Increasing self-regulatory strength can reduce the depleting effect of suppressing stereotypes. Personality and Social Psychology Bulletin, 33, 281-294. doi:10.1177/0146167206296101

Gailliot, M. T., Schmeichel, B. J., \& Baumeister, R. F. (2006). Self-regulatory processes defend against the threat of death: Effects of self-control depletion and trait self-control on thoughts and fears of dying. Journal of Personality and Social Psychology, 91, 49-62. doi:10.1037/0022-3514.91.1.49

Gailliot, M. T., Schmeichel, B. J., \& Maner, J. K. (2007). Differentiating the effects of self-control and self-esteem on reactions to mortality salience. Journal of Experimental Social Psychology, 43, 894-901. 
doi:10.1016/j.jesp.2006.10.011

Gaudry, E., Vagg, P., \& Spielberger, C. D. (1975). Validation of the state-trait distinction in anxiety research. Multivariate Behavioral Research, 10, 331-341. doi:10.1207/s15327906mbr1003 6

Hembree, R. (1988). Correlates, causes, effects, and treatment of test anxiety. Review of Educational Research, 58, 47-77.

doi:10.3102/00346543058001047

Hu, L. T., \& Bentler, P. M. (1995). Evaluating model fit. In R. Hoyle (Ed.), Structural equation modelling: Concepts, issues, and applications (pp. 76-99). Thousand Oaks, CA: Sage Publications.

Hu, L., \& Bentler, P. M. (1999). Cutoff criteria for fit indexes in covariance structure analysis: Conventional criteria versus new alternatives. Structural Equation Modelling, 6, 1-55. doi:10.1080/10705519909540118

Ising, M., Weyers, P., Janke, W., \& Erdmann, G. (2001). Die güte kriterien des SVF78 von Janke und Erdmann, einer kurzform des SVF120 [the psychometric properties of the SVF78 by Janke and Erdmann, a short version of the SVF120]. Zeitschrift für Differentielle und Diagnostische Psychologie, 22, 279-289. doi:10.1024//0170-1789.22.4.279

Janke, W., \& Erdmann, G. (2002). SVF78. Eine kurzform des stress verar beitungsbogens SVF120 [short version of the German coping questionnaire SVF120]. Göttingen, Germany: Hogrefe.

Lazarus, R., \& Folkman, S. (1984). Stress, appraisal, and coping. New York: Springer.

Laux, L., Glanzmann, P., Schaffner, P., \& Spielberger, C. D. (1981). Das state-trait-angst inventar [German state-trait anxiety inventory]. Göttingen, Germany: Hogrefe.

Miller, G. E., \& Blackwell, E. (2006). Turning up the heat. Inflamma- tion as a mechanism linking chronic stress, depression, and heart disease. Current Directions in Psychological Science, 15, 269-272. doi:10.1111/j.1467-8721.2006.00450.x

Mischel, W., Shoda, Y., \& Peake, P. K. (1988). The nature of adolescent competencies predicted by preschool delay of gratification. Journal of Personality and Social Psychology, 54, 687-696. doi:10.1037/0022-3514.54.4.687

Miyake, A., Friedman, N. P., Emerson, M. J., Witzki, A. H., Howerter, A., \& Wager, T. D. (2000). The unity and diversity of executive functions and their contributions to complex "frontal lobe" tasks: A latent variable analysis. Cognitive Psychology, 41, 49-100. doi:10.1006/cogp.1999.0734

Muraven, M., Tice, D. M., \& Baumeister, R. F. (1998). Self-control as limited resource: Regulatory depletion patterns. Journal of Personality and Social Psychology, 74, 774-789. doi:10.1037/0022-3514.74.3.774

Spielberger, C. D., Gorsuch, R. L., \& Lushene, R. E. (1970). Manual for the state-trait anxiety inventory. Palo Alto, CA: Consulting Psychologists Press.

Spielberger, C. D., \& Vagg, P. R. (1995). Test anxiety. Theory, assessment, and treatment. Washington, DC: Taylor \& Francis.

Tangney, J. P., Baumeister, R. F., \& Boone, A. L. (2004). High selfcontrol predicts good adjustment, less pathology, better grades, and interpersonal success. Journal of Personality, 72, 271-324. doi:10.1111/j.0022-3506.2004.00263.x

Yantis, S. (1998). Control of visual attention. In H. Pashler (Ed.), Attention (pp. 223-256). Hove, England: Psychology Press.

Zeidner, M. (1998). Test anxiety: The state of the art. New York: Plenum Press. 